\title{
Healthy properties of green and white teas: an update
}

\section{S. Pastoriza, ${ }^{a}$ M. Mesías, ${ }^{b}$ C. Cabrera ${ }^{\dagger a}$ and J. A. Rufián-Henares *a,c}

aDepartamento de Nutrición y Bromatología, Facultad de Farmacia, Campus de Cartuja S/N, I807I, Universidad de Granada, Granada, Spain

'Instituto de Ciencia y Tecnología de Alimentos y Nutrición (ICTAN-CSIC), José Antonio Novais I0, 28040 Madrid, Spain

'Instituto de Investigación Biosanitaria ibs.GRANADA, Universidad de Granada, Granada, Spain. E-mail: jarufian@ugr.es; Fax: +34 9582495 77; Tel: +34 958240749

\section{ABSTRACT}

Green tea has been consumed for centuries in Japan, China and Morocco. White tea, which is considered a variety of green tea, is mostly consumed in China and is very appreciated for its flavor. Currently the consumption of both types of tea has been extended to the western countries even as a functional ingredient. A group of polyphenols called catechins stands out among their bioactive components, the most abundant being the (-) epigallocatechin gallate, with high antioxidant power. Teas also contain other phenolic compounds such as gallic, caffeic, chlorogenic or cinnamic acids, quercetin and proanthocyanidols, caffeine, theophylline, L-theanine and minerals such as fluorine, manganese or chromium. Investigations have mainly been focused on their antioxidant potential and their implication in the prevention and treatment of degenerative diseases. Several studies have evaluated their role in cardiovascular diseases, body weight control, bone mass increase, protection against neurodegenerative diseases and improvement of type 2 diabetes, among other pathologies. The main points of controversy are the design and interpretation of epidemiological and human intervention studies and the lack of information on catechins availability, metabolism and biotransformation. This review compiles and analyzes the latest peer-reviewed papers published from 2002 up to February 2017, including systematic reviews and meta-analyses.

\section{INTRODUCTION}

Tea is the most consumed beverage in the world after water and is highly valued for its taste and aroma, its health benefits and for diverse socio-cultural reasons.I It is obtained by infusion of leaves and shoots of the species Camellia sinensis var. sinensis. The tea bush is cultivated in more than 45 countries. About 3 billion kilograms of tea are produced and consumed annuallyl worldwide and the largest tea producing countries are China, Japan, Taiwan, Indonesia, Thailand, Sri Lanka, Vietnam, Turkey, Kenya and Russia. Depending on the processing of the leaf, various types of tea are obtained, such as black tea, Oolong tea, green tea and white tea.I-3 In black tea, leaves are fermented through oxidation by polyphenoloxidase enzymes. In Oolong tea, leaves are subjected to a partial fermentation process. In green tea, the process of fermentation is avoided by the inactivation of the enzymes through a slight thermal treatment.4 Although there is no consensus on the definition, white tea is considered a green tea variety produced in very specific places, mainly in Fujian Province (China). 5 White tea is made entirely from leaf buds that are covered with downy and white hairs, from which its name is derived. The first leaves and buds are selected and subjected to a minimum processing by simple drying. White tea is highly valued for its organoleptic characteristics, as it provides an infusion with a soft and aromatic flavor and with floral and fruit notes.2,3 Some authors point out that white tea has less caffeine and more antioxidant compounds than green tea.2,5 However, other authors have argued that the composition of both caffeine and antioxidants, defined as the index between total catechins/polyphenols, is not a criterion of differentiation between green tea and white tea.2,3,6 The variability in the content of polyphenols and, therefore, in catechins, may be associated with factors such as growing conditions, climatology, processing, etc7,8 and even the conditions which the infusion is prepared under. 9

\section{I.I. Composition of tea leaves}

Pastoriza et al. / Food \& Function 8 (2017) 2650-2662 
Tea leaves are mainly composed of: (I) proteins ( $15-20 \%$ of the total referred to dry matter), where the major fraction is enzymes (polyphenoloxidases and lipoxygenase).I (2) Free amino acids ( $1-4 \%$ of the dry matter), where around $50 \%$ is L-theanine ( $\mathrm{N}$-ethyl-L-glutamine), which is a relevant compound in the flavor and health properties of green and white teas. $6 \mathrm{lt}$ is a non-proteinogenic amino acid, derived from glutamate, which appears only in a very small number of plants, including tea. It also contains glutamic acid, tryptophan, glycine, serine, tyrosine, arginine or lysine, among others. Among these amino acids, valine, phenylalanine, proline, leucine, isoleucine, tryptophan, threonine, lysine, histidine, arginine and tyrosine are found in a higher content in white tea when compared with green tea. By contrast, levels of theanine, glutamic acid, glutamine and aspartic acid are higher in green tea and lower in white tea. 10 (3) Carbohydrates (5-7\% of the dry matter) with polysaccharides such as cellulose, hemicellulose, pectins, glucose, sucrose, arabinose or ribose.I (4) Lipids, present in a very low amount as glycerophospholipids, triterpene alcohols, fatty acids and sterols. (5) Vitamins, predominantly vitamin $C$ and some of group $B$. (6) Xanthic bases, including caffeine and theophylline and theobromine at a very low concentration. 5 Tea leaves contain about $2-5 \%$ caffeine.II The content of caffeine in the infusion of green tea is approximately $15-25 \mathrm{mg}$ per $150 \mathrm{~mL} .12$ This content is approximately $15 \%$ lower in white tea, 13 although it could be influenced by the brewing time, leaf size and water temperature. In general, tea infusions from tea in bags, where leaves are quite crushed, contain a higher amount of caffeine than those from tea leaves. 12 (7) Phenolic compounds (26\% of the dry extract of green tea). (8) Minerals, including fluorine, manganese, copper and chromium.5,13-18 Tables 1 and 2 include data about the content of some minerals in leaves and infusions of green tea and white tea, respectively. (9) Other compounds, such as heterosides of terpene alcohols, pigments (chlorophyll and carotenoids), and aroma compounds (i.e. 2-hexenal, 3-hexenol, linalool, geraniol, etc.).

In black tea, the oxidation process by the polyphenoloxidase enzyme causes remarkable changes in the chemical composition of the leaf.I These changes include oxidation of phenolic compounds, which results in oxidized compounds such as theaflavins and thearubigins, enzymatic hydrolysis of proteins, oxidative deamination of amino acids, oxidation of lipids and carotenoids, degradation of chlorophyll, release of caffeine, loss of vitamin $\mathrm{C}$ or changes in sensory attributes such as brown-dark color, more marked empyreumatic aroma and more bitter taste. 2 These negative changes are not produced in green tea and white tea and, therefore, the content of bioactive compounds in both types of tea is higher than in black tea and, consequently, their beneficial effects on health are more remarkable.

\subsection{Content of phenolic compounds}

Polyphenols are the most relevant family of phytochemicals in terms of beneficial effects on human health.19 Among them, flavonoids constitute a very extensive group and are distributed in a great variety of vegetables. They have a common basic structure of $(\mathrm{C} 6-\mathrm{C} 3-\mathrm{C} 6)$ diphenylpropane, which usually forms an oxygenated heterocycle. Flavonoids are usually bound to sugars (glycosides) and for that reason they tend to be watersoluble. Green and white tea are especially rich in flavonoids, specifically catechins. 12 In this line, the consumption of green tea is considered the main source of catechins in the diet.20-22 The content of phenolic acids (gallic acid, benzoic acid, cinnamic acid, chlorogenic acid, caffeic acid), gallic esters of glucose (gallic tannins), quercetin and proanthocyanidols is also highlighted.II,21,22 Total polyphenols range between 10.60-25.95 g per $100 \mathrm{~g}$ in white tea and between 13.7-24.7 g per $100 \mathrm{~g}$ in green tea.2,23,24

The most abundant catechins in green and white teas are $(-)$ epigallocatechin gallate (EGCG), representing approximately $59 \%$ of the total catechins; (-) epigallocatechin (EGC), which accounts for $19 \%,(-)$ epicatechin gallate (ECG) in a proportion close to $13 \%$ and $(-)$ epicatechin (EC), around $6 \%$ of the total.12,25,26 According to Hilal and Engelhardt2 and Carloni et al. 13 the catechin content in tea ranges from 9.89 to $17.00 \mathrm{~g}$ per $100 \mathrm{~g}$ in green tea, from 7.94 to $16.56 \mathrm{~g}$ per $100 \mathrm{~g}$ in white tea and from 0.74 to $10.00 \mathrm{~g}$ per $100 \mathrm{~g}$ in black tea. The catechin content is consistent with the fermentation degree, 
since black, white and green teas are fully, slightly and non-fermented, respectively. 10 Levels from 2.76 to $9.34 \mathrm{~g}$ per $100 \mathrm{~g}$ for catechins in white tea have also been reported.24 Regarding EGCG, the amounts change between 4.40-9.60 g per $100 \mathrm{~g}$ in green tea and between 5.23-9.49 g per $100 \mathrm{~g}$ in white tea. Cabrera et al.14 observed that the content of EGCG in green tea leaves was higher than $80 \mathrm{mg} \mathrm{g-I}$, whereas in black tea it did not exceed $30 \mathrm{mg} \mathrm{g-I}$. Wu and Wei27 reported that one cup of green tea ( $2.5 \mathrm{~g}$ tea leaves per $200 \mathrm{~mL}$ water) may contain $90 \mathrm{mg}$ of EGCG and Johnson et al.28 estimated that the daily intake of $3-5$ cups of green tea $(720-1200 \mathrm{~mL})$ could provide up to $250 \mathrm{mg}$ of catechins.

Due to the beneficial properties of the phenolic compounds and their high content in tea, tea extracts obtained from the soluble fraction of the unfermented leaves are widely used as an ingredient in food and cosmetics. Commercial extracts contain different amounts of polyphenols, where about $80 \%$ may be represented by catechins and more than $45 \%$ by EGCG. EGCG has an activity against reactive oxygen species quite superior to vitamins $C$ and E,29 which justifies the high antioxidant capacity associated with tea.

The more intact the leaves appear, the greater is the flavonoid content. This content decreases with the manipulation of the leaves, as in powdered tea or during the decaffeination process. 12 In addition, the influence of infusion conditions on the catechin content is significant. Thereby, using almost boiling water $\left(98{ }^{\circ} \mathrm{C}\right)$ and an infusion time of 7 minutes leads to a high extraction of catechins and polyphenols and, consequently, to a high total antioxidant capacity.30 Moreover, optimal sensorial characteristics are achieved under these conditions, while longer infusion times provide bitter taste and excessive astringency.31

\section{BENEFICIAL EFFECTS OF WHITE AND GREEN TEA CONSUMPTION}

Recent studies have revealed that green and white teas have positive biological activities against chronic diseases such as cancer, metabolic syndrome, type 2 diabetes, cardiovascular and neurodegenerative pathologies, among others. These protective properties are related to the potent antioxidant and antiinflammatory activities of xanthic bases (caffeine and theophylline), essential oils (green tea and white tea are the two types of tea with the highest content), minerals (F, Mn, $\mathrm{Cr}$ ), L-theanine and, mostly, catechins and other phenolic compounds. 12,32

Caffeine acts on the central nervous system by stimulating attention, facilitating the association of ideas and reducing the sensation of fatigue. Some of the effects caused by caffeine are influenced by the content of theophylline, which also has inotrope, vasodilator, diuretic and bronchodilator action. 12,25 Essential oils, which are abundant in green tea and white tea, facilitate digestion. 12 Catechins and in particular EGCG have low bioavailability when orally ingested. 33 Only a small percentage is absorbed at the level of the small intestine and passes into the bloodstream, reaching maximum plasma concentrations between I-3 hours after consumption. Some authors indicate that the secondary metabolites derived from the intake of flavonoids could be detected in blood and urine. For that reason, it is thought that the observed biological effects are possibly due to these secondary metabolites rather than the flavonoids themselves, which are detected in their original form in very low quantities.34 The bioavailability of phenolic tea compounds has been extensively reviewed by Lambert et al.,35 who pointed out the need to expand in vivo studies to better confirm the physiological effects of green and white tea consumption. However, whatever their bioavailability, there are many scientific reports relating the antioxidant and antiinflammatory effects of EGCG to its ability to modulate mitochondrial functions, impacting mitochondrial biogenesis, bioenergetic control, etc. 36

\section{I. Antioxidant activity}

Oxidative stress is considered a biochemical imbalance caused by excessive production of reactive oxygen species, or by a decrease in oxidizing systems. It is related to aging and promotes the presence 
or complications of diseases such as atherosclerosis, diabetes mellitus, Alzheimer's disease or various types of cancer, as well as inflammatory processes and ischemia/perfusion. Among the properties of catechins, their antioxidant capacity and high potential against oxidative stress are highlighted.36 This fact explains their antidiabetic, anticancer and antiatherogenic actions. The molecular mechanisms, by which this protective action is achieved, are not precisely known. However, it has been suggested that catechins may be involved in the insulin signaling pathway, regulation of various transcription factors, inhibition of prooxidant enzymes such as nitric oxide synthetase, lipoxygenase, cyclooxygenase and xanthine oxidase, metal chelation such as $\mathrm{Fe}$ and $\mathrm{Cu}$ involved in oxidative processes and induction of antioxidant enzymes such as glutathione S-transferase and superoxide dismutase.12,37-42 In this way, consuming white tea increases the expression of genes related to antioxidant capacity such as Nrf2, Gst, $\mathrm{Nqol}$ and Hol.4I,43 Catechins protect against cell damage caused by free radicals at the level of proteins, lipids and DNA.2, I4 Diseases such as cancer or cardiovascular disorders are thought to be produced or aggravated by free radicals in a similar way to premature cell aging. Following the most recent research, Table 3 describes the main biological effects attributed to catechins, and especially to EGCG, which are present in green and white teas.

Several studies have shown that the antioxidant capacity of green tea is higher than that of other types of tea and other plant products. Using the FRAP (Ferric Reducing Ability of Plasma) method, the total antioxidant capacity (TAC) of green tea is greater than that of black tea (38 and $17 \mu \mathrm{M}$ trolox per $g$ tea per $L$ infusion, respectively).44 Gorjanovic et al.22 determined the TAC in green, white, black and Oolong tea infusions applying the DPPH (I,I-diphenyl-2-picrylhydrazyl) method, showing values of 4.80 $\pm 0.40,3.66 \pm 0.26,4.45 \pm 0.57$ and $3.88 \pm 0.06 \mathrm{mM}$ trolox per $\mathrm{L}$, respectively. In addition, according to the Oxygen Radical Absorbance Capacity (ORAC) method, the TAC of green tea45 is higher than that of other vegetables such as garlic, spinach and Brussel sprouts (Table 4). In this line, Carlsen et al.46 collected data on TAC measured by the FRAP method in more than 3100 foods, beverages, spices, herbs and food supplements consumed worldwide. This study proved that the infusion of unfermented tea leaves had higher TAC values than other products such as orange, grape or tomato juice. Gorjanovic et al.22 indicated that the antioxidant capacity of the characteristic compounds of green tea and white tea, determined by the polarographic method, ranges in the following order: EGCG > ECG > EGC > gallic acid > EC > caffeine.

According to some human intervention studies, a moderate consumption of green tea ( $I-6$ cups per day) increases the total antioxidant capacity of the plasma and, therefore, promotes a greater protection of the organism against the oxidative damage caused by free radicals. 10,47 For this reason, including the consumption of green or white tea in the usual diet has been recommended. 10,12,48 Biomarkers of the oxidative status have also shown to decrease with a regular consumption of green tea and microencapsulated extracts over a period of $\mathrm{I}-4$ weeks. 12 However, it is important to emphasize that for the effects to be expressed, tea should be consumed as an additional component of a balanced diet in addition to a healthy lifestyle.

Almajano et al.8 observed a neuroprotective effect of white tea in a study with cell cultures. Results showed a reduction of the oxidative stress associated with brain damage. This effect was attributed to the content of catechins and other flavonols. Oxidative stress as a result of the production of reactive oxygen species (ROS) is known to be an important factor in aging and neurodegenerative disorders such as Alzheimer's, Parkinson's or Huntington's disease.49

\subsection{Effects on stress}

Although green tea contains caffeine, its consumption produces a noticeable relaxation effect, which is attributed to the presence of catechins, or L-theanine or both compounds. I,50 Furase et al.25 indicated that EGCG has sedative and hypnotic effects at the brain level, by acting partially at the level of GABA 
receptors moderating the response to acute stress. In addition, a positive effect against anxiety in mice has been observed.I,51,52 The sedative effect is enhanced by the presence of L-theanine. This amino acid is considered as a neuroprotective agent that reduces psychological and physiological stress.53-55 However, the consumption of green tea does not induce sleep due to the caffeine content, which produces the opposite effect, stimulating the central nervous system and promoting wakefulness.56 Effects attributed to L-theanine also include promoting the secretion and functions of certain neurotransmitters in the central nervous system.I For all these reasons, the consumption of green tea may be advisable in certain diseases associated with stress and anxiety. 25

\subsection{Anti-mutagenic and anticancer activity}

Anticancer effects of green tea have been demonstrated in numerous studies with various cell lines, showing an inhibition of cell growth and an induction of apoptosis by catechins. 23,37,47 Catechins possess antimutagenic activity, avoiding the formation of mutagens (i.e., nitrosamines) or preventing the expression of mutagenicity (i.e., polycyclic aromatic hydrocarbons). 57 García-Rodríguez et al.58 observed that mice consuming green tea presented reduced genotoxic damage induced by metallic compounds, such as $\mathrm{Cr}(\mathrm{VI})$ compounds. This fact suggests a chemo-preventive effect of its antioxidant components. On the other hand, EGCG has been found to block urokinase, an enzyme that seems to be involved in the proliferation and diffusion of tumors.39,40,59,60

In cell cultures and in experimental animals, EGCG has been shown to protect against carcinogenic processes induced in different organs, such as skin, lung, stomach, pancreas, duodenum, colon, prostate and also in breast cancer.39,61-63 This protection has been associated with increased apoptosis or programmed cell death, which is a key strategy for the removal of neoplastic cells. The protective effect also includes a decrease in cellular proliferation, its antioxidant and antiinflammatory activities, the specific induction of detoxifying enzymes and a selective effect on the intestinal microbiota that facilitates its development.38,39,62,64 In addition, ECGC seems to have an anti-angiogenic effect since it prevents the growth of blood vessels in tumors. 65

Several epidemiological studies carried out in countries with a high tea consumption, such as Japan or China, suggest that green tea may have a protective effect against certain types of cancer. However, the results obtained require further investigation since they are not conclusive.63,66,67 In this sense, breast cancer has been shown significantly less frequent in Asian women with high soybean and green tea consumption. It suggests that soybean phytochemical compounds may potentiate the inhibitory effect of green tea on the progression of breast cancer.68

Currently, the chemoprevention of cancer through the use of natural components of diet has acquired great interest. In this respect, polyphenols ingested through foods and beverages seem to have very promising effects, although the mechanisms of action are still not well established. Singh et al.69 indicated that EGCG has high potential in cancer prevention with the advantages of being a safe, lowcost and bioavailable non-toxic natural agent. These authors consider that it could be used alone or in combination with other treatments, in the prevention and treatment of tumor processes. Traditional pharmacological treatments can often destroy cancer cells and some healthy cells. However, EGCG seems to act selectively on the damaged cells.

\subsection{Effect on blood pressure and cardiovascular risk}

The consumption of green tea has been associated with the protection against stroke, hypertension and atherosclerosis, due to its antithrombotic and anti-inflammatory effects, among other reasons.70,7I It decreases blood levels of total cholesterol, LDL-c and its oxidation. The explanation is very complex and most studies are focused on the role of EGCG on the lipid profile.72,73 Epidemiological and observational studies in humans suggest that a regular consumption of green tea may be associated with 
a lower cardiovascular risk.21,71,73 Green tea has been demonstrated to decrease the micellar solubility of cholesterol at the intestinal level, reducing then its absorption. At the same time, it improves endothelial function, protects LDL from oxidation, increases high density lipoprotein levels (HDL) and increases the total antioxidant capacity of plasma.48,74,76 On the other hand, gallic acid, present in remarkable amounts in tea leaves, can interact with the function of P-selectin, an adhesion molecule involved in atherothrombosis which mediates the interactions between leukocyteendothelium, leukocyte-platelet and platelet-platelets. 70 Studies in humans have shown that the oral intake of green tea extracts with a high catechin content increases the resistance of plasma LDL to oxidation.39 As the main strategies for modifying the blood lipid profile include medication, lifestyle modification and consumption of certain plant products, green tea and white tea consumptions are options which should be considered and may provide interesting avenues for future research.

Studies with experimental animals have evaluated the effects of the administration of catechin concentrates equivalent to the content of 8-10 cups of green tea. Catechins seem to inhibit the action of the enzyme that converts angiotensin I into angiotensin II, a potent vasoconstrictor, and therefore its action is suppressed. However, it is also indicated that the caffeine content of green tea, although low, may counter the effect of catechins since it could raise the blood pressure.12 Most studies with experimental animals have observed that green tea catechins decrease the blood pressure.70 Yang et al.60 concluded that a regular consumption of $120 \mathrm{~mL}$ per day of green tea for I year significantly reduces the risk of developing hypertension. In another study conducted in China with 1507 subjects, it was found that the daily consumption of around $600 \mathrm{~mL}$ of green tea for one year reduced the risk of hypertension compared with the control group of subjects with similar body mass index, diet, and lifestyle.75 This effect may be due to its vasodilator action, protection against endothelial diffusion and antioxidant and lipid-lowering properties.

\subsection{Antibacterial and antiviral activity}

In 1923, the British Army's health authority recommended hat all soldiers should carry tea in their canteens to prevent typhoid fever.12 The effectiveness of green tea in any type of diarrhea has been known in Asia since ancient times. Nowadays it is known that it inhibits the multiplication and growth of numerous bacteria including some species of Salmonella and Bacillus,8,39 Helicobacter pylori,77 Staphylococcus aureus,78 Clostridium perfringens,79 Candida albicans80 and Pseudomonas aeruginosa.8I In contrast, green tea is safe for the intestinal microbiota, which is a great advantage over other bactericidal agents. Recent publications indicate that green tea could promote the development of some species of Bifidobacterium.82 These aspects have been recently reviewed by Siddiqui et al.83 These authors affirm that extracts of tea could be used as antimicrobial agents with new mechanisms of resistance.

Regarding its action against viruses, the use of green tea on influenza virus is well known, especially at the earliest stage,84 as well as on the Herpes simplex virus.85 EGCG has also been shown to inhibit HIV-I replication by the inhibition of reverse Review Food \& Function transcriptase.39 In addition, EGCG from green tea has received important attention for its effects on Zika virus infection in Brazil.86 According to Mahmood et al.87 the antiviral activity of green tea shows a promising future as a popular drink and also as a potential therapeutic agent.

\subsection{Effect on oral health}

Green tea has a protective effect against dental caries, which is attributable to its fluoride content and the bactericidal effect of polyphenols.88,89 Catechins not only avoid the formation of tartar by the prevention of gingivitis and halitosis, but also act by eliminating bacteria involved in the cariogenic process (Escherichia coli, Streptococcus salivarius, Porphyromonas gingivalis or Streptococcus mutans). Moreover, catechins inhibit the activity of salivary $\alpha$-amylase, decreasing the cariogenic potential of 
hydrocarbon foods and caries formation.12,89-9| Linke and LeGeros90 indicated that the frequent intake of green tea significantly reduces the risk of dental caries, even with the concomitant presence of sugars in the diet. Some authors even suggest that green tea extracts may exert a preventive effect on oral cancer.12,92 Currently, green tea is widely used in products intended for oral hygiene such as tooth paste or mouthwashes with chlorhexidine.89

\subsection{Protection against solar radiation}

Several epidemiological, clinical and biological studies have demonstrated the carcinogenicity of intense and prolonged exposure to ultraviolet light. EGCG and other tea catechins are considered potent topical protective agents against this type of radiation, also preventing premature photoaging, certain skin pathologies and even carcinogenic processes. 12,85,93,94 Currently, green tea is widely used in cosmetics and in some dermatological treatments, for example against acne.

\subsection{Effects on the processes of lipolysis and thermogenesis}

In vitro assays performed with green tea extracts with a high catechin content (approximately $25 \% \mathrm{w} / \mathrm{w}$ ) have shown their ability to drastically inhibit gastric lipase and, to a lesser extent, pancreatic lipase under physiological conditions. Consequently, lipolysis of long chain triglycerides is reduced by $37 \% .95$ Similarly, in vitro tests have also demonstrated that green tea extracts interfere in the process of emulsifying fats, a preceding and essential step for the intestinal absorption of fats.25,95

Green tea may influence thermogenesis, not only by the action of caffeine, but also because EGCG can increase energy expenditure by acting on cAMP levels, which suggests a potential effect on body weight control.96,97 Catechins are known to activate AMP-activated protein kinase (AMPK), an enzyme involved in the control of energetic metabolism both at cellular and organic levels.96,98 Activation of AMPK inhibits the process of differentiation of adipocytes and the expression of lipogenic enzymes such as fatty acid synthetase or acetyl-CoA carboxylesterase. Catechins also have the ability to promote leptin release and attenuate the symptoms associated with metabolic syndrome. However, the molecular mechanisms responsible for these changes are unknown.2I In vitro studies have shown that EGCG interacts with noradrenaline to stimulate the thermogenesis of brown adipose tissue and to regulate various enzymes related to lipid anabolism and catabolism.99 In this way, extracts of white tea stimulate lipolysis and, at the same time, inhibit adipogenesis in human adipocytes. 100 An inhibition of the expression of genes involved in gluconeogenesis and in the synthesis of fatty acids, triglycerides and cholesterol has been observed in rodents.39 A regular consumption of green tea over a period of more than 10 years has been correlated with a lower percentage of body fat. 101,102

\subsection{Effect on glycemic control}

EGCG not only helps to regulate blood glucose levels but also renovates impaired pancreatic $\alpha$-cells which are responsible for the production of insulin. 12,103,104 Swen75 observed that the consumption of $1.5 \mathrm{~g}$ of green tea extract 20 minutes before an oral dose of glucose significantly reduced blood glucose levels. This effect could be due to the inhibitory effect of catechins present in green and white teas on the activity of $\alpha$-amylase and $\alpha$-glucosidase enzymes, which could control postprandial hyperglycemia. 105 The consumption of white tea also improves glucose tolerance and insulin sensitivity and improves the levels of protein oxidation due to the production of ROS in diabetes. 104 More details about the mechanisms underlying the effect of green tea consumption on diabetes are included in the recent revision reported by Ferreira et al. 106

\subsection{Other effects}

Green and white teas intensify the immune function as they protect against oxidants and free radicals. Their usefulness against insect bites, mainly due to the anti-inflammatory and anti-hemorrhagic action, is well known. Several studies pointed out a positive effect on osteoporosis, since green tea polyphenols 
modulate osteoblastogenesis and osteoclastogenesis, by increasing the bone mineral density due to their antioxidant and anti-inflammatory activities.107,108 Other positive effects are associated with the prevention of renal and hepatic calculi, and the prevention of senile cataract and positive effects in patients with epilepsy, Parkinson's disease, depression or stroke.12,32,109-1 I3 Regarding the effects on Parkinson's disease, green and white teas seem to act through a modulation of oxidative stress in the brain, neuroinflammation, protein aggregation and neuronal death. I I 2, I I 4, II 5 The therapeutic potential of green tea in the pathology of fatty liver of non-alcoholic etiology has also been described.19,116 However, the authors agree that additional research is needed to confirm these data.

\section{POSSIBLE NEGATIVE EFFECTS OF WHITE AND GREEN TEA CONSUMPTION}

Although the caffeine content is not very high, the consumption of green and white teas is not recommended in people especially sensitive to xanthic bases. Additionally, consumption is not recommended in patients with serious cardio- vascular problems or in those with gastroduodenal ulcer, since tea facilitates gastric secretion. I I 7 It is advisable to reduce their consumption to I-2 cups per day in pregnant women since tea can reduce the bioavailability of folic acid. In general, their consumption should be reduced in people with anemia due to the possible interaction of tea tannins with $\mathrm{Fe}$ and especially in the case of megaloblastic anemia.28 The presence of aluminum may be rather elevated in some types of tea because of a notable influence of cultivated and processed soil levels. 16 On the other hand, drinking too hot tea may increase the risk of esophageal cancer.1/8 Finally, a very high consumption of green or white tea would lead to excessive intake of flavonoids, which would give rise to the formation of ROS that would cause damage in DNA, lipid membranes and proteins. I 17

\section{CONCLUSIONS}

The health effects associated with the consumption of green and white teas include protection against hypertension and cardiovascular diseases, promotion of oral health, control of body weight, antibacterial and antiviral activity, protection against UV radiation, increase of bone mineral density, and antifibrotic and neuroprotective properties, among others. These effects are related to their high content of polyphenols and in particular catechins, where EGCG stands out due to its high antioxidant potential, which even surpasses that found in vitamins $C$ and $E$. The effects are also related to the presence of caffeine and L-theanine, an amino acid with interesting biological effects. Green and white teas may also be a source of some minerals, including $\mathrm{Mn}$ and F. Recent studies indicate that the consumption of green and white teas may contribute to reduce the risk of some types of cancer. The use of natural antioxidants such as polyphenols are presented as an interesting proposal for the prevention and therapy of carcinogenic processes and therefore their mechanisms of action have aroused great scientific interest. Several authors advise the use of catechins present in tea as a preventive or adjuvant treatment to other chemical treatments. Although results about EGCG activity are highly promising, a more precise knowledge of the molecular mechanisms of action in vivo is needed. Following the effects described on health, green tea has been included in the list of foods with functional properties. Scientific evidence is very promising but future studies are necessary to test these findings taking into account environmental, dietary and lifestyle factors. The available data are derived mainly from epidemiological studies or the extrapolation of results obtained from tests with experimental animals where extracts of tea rich in catechins, especially with a high content of EGCG, were administered. Several authors agree on the need to expand in vivo evaluations on the absorption, distribution and metabolism of their main compounds with antioxidant activity. Moreover, it would be interesting to carry out additional studies with a habitual consumption extended in time more than studies designed with a very high consumption during a short period of time. For instance, cancer studies generally compare a low or no consumption versus a high consumption (even 10 cups per day). Regarding the research carried out with extracts, a better control of factors such as dose or formulation is necessary. This fact is essential in order to better identify the product tested and the population which it can exercise the benefit in. In conclusion, further research and well-designed additional studies (observational, epidemiological and nutritional 
intervention) are needed to define the current magnitude of health effects of tea, to establish the range of safety of the consumption associated with beneficial effects and to elucidate the possible mechanisms of action as a basis for future nutritional claims related to both green and white teas.

Green and white teas have a number of advantages that make them a very good alternative to other beverages which are widely consumed and less healthy. They are beverages with a pleasant flavor (flowers and fruit aroma with low levels of bitterness and astringency) that are even commercialized flavored with other fruits and flowers. They are popular beverages, socially well accepted, economical, safe and consumed daily by hundreds of millions of people in the five continents. Currently, these teas are widely used in the preparation of various foods and cosmetics based primarily on the antioxidant activity, acting as a natural, effective, and safe preservative. However, their consumption in western diets is still limited and sporadic. Due to the high content of antioxidants, it is recommended that tea consumption be included in a nutritional, varied and balanced diet. Some authors even define the consumption of green and white teas as a 'gift of nature' for human health.

\section{ACKNOWLEDGEMENTS}

This work was supported by the project AGL2014-53895-R from the Spanish Ministry of Economy and Competitiveness and the European Fund of Regional Development (FEDER). This paper is dedicated to Prof. Carmen Cabrera, who passed away in 2016. We thank Glenn K. Harding for proofreading the English-language manuscript.

\section{REFERENCES}

I H. McKinley and M. Jamieson, Handbook of Green Tea and Health Research, Nova Publishers, New York, 2009.

2 Y. Hilal and U. Engelhardt, Characterisation of white tea - comparison to green and black tea, J. Consum. Prot. Food Saf., 2007, 2, 4I4-42I.

3 C. Espinosa, J. A. López-Jiménez, L. Cabrera, E. Larqué, M. P. Almajano, M. B. Arnao, S. Zamora and F. Pérez-Llamas, Protective effect of white tea extract against acute oxidative injury caused by adriamycin in different tissues, Food Chem., 2012, 134, 1780-1785.

4 N. Muller, S. Ellinger, B. Alteheld, G. Ulrich-Merzenich, H. K. Berthold, H. Vetter and P. Stehle, Bolus ingestion and white and green tea increases the concentration of several flavan-3-ols in plasma, but does not affect markers of oxidative stress in healthy non-smokers, Mol. Nutr. Food Res., 2010, 54, $1636-$ 1645.

5 U. J. Unachukwu, S. Ahmed, A. Kavalier, J. T. Lyles and E. J. Kennelly, White and green teas (Camellia sinensis, var. sinensis): variation in phenolic, methylxanthine, and antioxidant profiles, J. Food Sci., 2010, 75, 54I-548.

6 A. Alcazar, O. Ballesteros, J. M. Jurado, F. Pablos, M. J. Martin, J. L. Vilches and A. Navalon, Differentiation of green, white, black, Oolong, and Pu-erh teas according to their free amino acids content, J. Agric. Food Chem., 2007, 55, 5960-5965.

7 G. Santana-Rios, G. A. Orner, A. Amantana, C. Provost, S. Y. Wu and R. H. Dashwood, Potent antimutagenic activity of white tea in comparison with green tea in the Salmonella assay, Mutat. Res., 200I, 495, 6I-74.

8 M. P. Almajano, I. Vila and S. Gines, Neuroprotective effects of white tea against oxidative stressinduced toxicity in striatal cells, Neurotox. Res., 20I I, 20, 372-378.

9 G. Rusak, D. Komes, S. Likic, D. Horzic and M. Kovac, Phenolic content and antioxidative capacity of green tea and white tea extracts depending on extraction conditions and the solvent used, Food Chem., 2008, I10, 852-858.

10 W. Dai, D. Xie, M. Lu, P. Li, H. Lv, C. Yang, Q. Peng, Y. Zhu, L. Guo, Y. Zhang, J. Tan and Z. Lin, Characterization of white tea metabolome: Comparison against green and black tea by a non targeted metabolomics approach, Food Res. Int., 2017, 96, 40-45. 
II N. Khan and H. Mukhtar, Tea polyphenols for health promotion, Life Sci., 2007, 8I, 5I9-533.

12 C. Cabrera and R. Giménez, in Tratado de Nutrición, ed. A. Gil, Editorial Médica Panamericana, Madrid, Café, té, cacao y productos derivados, 2010, pp. 353-355.

I3 P. Carloni, L. Tiano, L. Padella, T. Bacchetti, C. Customu, A. Kay and E. Damiani, Antioxidant activity of white, green and black tea obtained from the same tea cultivar, Food Res. Int., 2013, 53, 900-908.

14 C. Cabrera, R. Giménez and M. C. López, Determination of tea components with antioxidant activity, J. Agric. Food Chem., 2003, 5I, 4427-4435.

I5 R. Street, I. Szakova, O. Drabek and L. Mladkova, The status of micronutrients ( $\mathrm{Cu}, \mathrm{Fe}, \mathrm{Mn}, \mathrm{Zn}$ ) in tea and tea infusions in selected samples imported to the Czech Republic, Czech J. Food Sci., 2006, 24, 62-7I.

16 T. Karak and R. M. Bhagat, Trace elements in tea leaves, made tea and tea infusion: a review, Food Res. Int., 2010, 43, 2234-2252.

$17 \mathrm{~J}$. Brzezicha-Cirocka, M. Grembecka and P. Szefer, Monitoring of essential and heavy metals in green tea from different geographical origins, Environ. Monit. Assess., 2016, 188, 183.

18 C. Y. Peng, H. M. Cai, X. I. Zhu, D. X. Li, Y. Q. Yang, R. Y. Hou and X. C. Wan, Analysis of naturally occurring fluoride in commercial teas and estimation of its daily intake through tea consumption, J. Food Sci., 2016, 81, H235-H239.

19 M. González-Castejón and A. Rodríguez-Casado, Dietary phytochemicals and their potential effects on obesity: a review, Pharmacol. Res., 20II, 64, 438-455.

$20 \mathrm{~L}$. Arab and J. B. Blunberg, Introduction of the proceedings for the Fourth International Scientific Symposium on Tea and Human Health, J. Nutr., 2008, 138, 1526-1528.

21 USDA Database for the flavonoid contents of selected foods. US Department of Agriculture, Beltsville, https://www.ars.usda.gov/northeast-area/beltsville-md/beltsvillehuman-nutrition-researchcenter/nutrient-data-laboratory/docs/usda-database-for-the-flavonoid-content-of-selectedfoods-release-

31-december-2013/ (accessed February 2017).

22 S. Gorjanovic, D. Komes, F. T. Pastor, A. Belscak-Cvitanovic, L. Pezo, I. Hecinmovic and D. Suznjevic, Antioxidant capacity of teas and herbal infusions: polarographic assessment, J. Agric. Food Chem., 2012, 60, 9573-9580.

23 F. Hajiaghaalipour, J. Sanusi and M. S. Kanthimathi, Temperature and Time of Steeping Affect the Antioxidant Properties of White, Green, and Black Tea Infusions, J. Food Sci., 2016, 8I, H246-H254.

24 J. Tan, U. H. Engelhardt, Z. Lin, N. Kaiser and B. Maiwald, Flavonoids, phenolic acids, alkaloids and theanine in different types of authentic Chinese white tea samples, J. Food Compos. Anal., 2017, 57, 815.

25 M. Furase, N. Adachi, S. Tomonaga, M. Yamane and D. M. Denbow, Handbook of green tea and health research, ed. H. McKinley and M. Jamieson, Nova Science Publishers Inc., New York, 2009, Central functions of green tea components.

26 Y. Zhao, P. Chen, L. Lin, J. M. Harnly, L. Yu and Z. Li, Tentative identification, quantitation, and principal component analysis of green pu-erh, green, and white teas using UPLC/DAD/MS, Food Chem., 201I, 126, 1269-1277.

27 C. D. Wu and G. X. Wei, Tea as a functional food for oral health, Nutrition, 2002, 18, 443-444.

28 R. Johnson, S. Bryant and A. L. Huntley, Green tea and green tea catechin extracts: an overview of the clinical evidence, Maturitas, 20I2, 73, 280-287.

$29 \mathrm{H}$. Schroeter, J. P. Spencer, C. Rice-Evans and R. J. Williams, Flavonoids protect neurons from oxidized low-density-lipoprotein-induced apoptosis involving c-JunN-terminal kinase (JNK) and capase-3, Biochem. J., 200I, 358, 547-557.

30 V. C. Rodrigues, M. V. da Silva, A. R. dos Santos, A. A. F. Zielinski and C. W. I. Haminiuk, Evaluation of hot and cold extraction of bioactive compounds in teas, Int. J. Food Sci. Technol., 2015, 50, 20382045.

3I S. Pastoriza, S. Pérez-Burillo and J. A. Rufián-Henares, How brewing parameters affect the healthy profile of tea, Curr. Top. Food Sci. Technol., 2017, 14, 7-12. 
32 R. Cooper, Green tea and theanine: health benefits, Int. J. Food Sci. Nutr., 2012, 63, 90-97.

33 G. C. Tenore, P. Campiglia, D. Giannetti and E. Novellino, Simulated gastrointestinal digestion, intestinal permeation and plasma protein interaction of white, green, and black tea polyphenols, Food Chem., 2015, 169, 320-326.

34 J. L. Di Gesso, J. S. Kerr, Q. Zhang, S. Raheem, S. K. Yalamanchili, D. O’Hagan, C. D. Kay and M. A. O'Connell, Flavonoid metabolites reduce tumor necrosis factor- $\alpha$ secretion to a greater extent than their precursor compounds in human THP-I monocytes, Mol. Nutr. Food Res., 20 I5, 59, II43-I I54.

35 J. D. Lambert, S. Sang, A. Y. Lu and C. S. Yang, Metabolism of dietary polyphenols and possible interactions with drugs, Curr. Drug Metab., 2007, 8, 499-507.

36 M. R. De Oliveira, S. F. Nabavi, M. Daglia, L. Rastrelli and S. M. Nabavi, Epigallocatechin gallate and mitochondria-A story of life and death, Pharm. Res., 2016, 104, 70-85.

37 J. D. Lambert and C. S. Yang, Mechanisms of cancer prevention by tea constituents, J. Nutr., 2003, 133, 3262-3267.

38 A. Mittal, M. S. Pate, R. C. Wylie, T. O. Tollesfsbol and S. K. Katiyar, EGCG down regulates telomerase in human breast carcinoma MCF-7 cells, leading to suppression of cell viability and induction of apoptosis, Int. J. Oncol., 2004, 24, 703-710.

39 N. T. Zaveri, Green tea and its polyphenolic catechins: medicinal uses in cancer and non-cancer applications, Life Sci., 2006, 78, 2073-2080.

40 I. C. Arts, A review of the epidemiological evidence on tea, flavonoids, and lung cancer, J. Nutr., 2008, I38, I56I-1566.

4 I C. Espinosa, F. Pérez-Llamas, F. A. Guardiola, M. A. Esteban, M. B. Arnao, S. Zamora and J. A. LópezJiménez, Molecular mechanisms by which white tea prevents oxidative stress, J. Physiol. Biochem., 20I4, 70, $891-900$.

42 A. Winiarska-Mieczan, The potential protective effect of green, black, red and white tea infusions against adverse effect of cadmium and lead during chronic exposure e A rat model study, Regul. Toxicol. Pharmacol., 2015, 73, 52I-529.

43 C. Espinosa, J. A. López-Jiménez, F. Pérez-Llamas, F. A. Guardiola, M. A. Esteban, M. B. Arnaoc and S. Zamora, Long-term intake of white tea prevents oxidative damage caused by Adriamycin in kidney of rats, J. Sci. Food Agric., 2015, 96, 3079-3087.

$44 \mathrm{~S}$. Langley-Evans, Antioxidant potential of green and black tea determined using the ferric reducing power (FRAP) assay, Int. J. Food Sci. Nutr., 2000, 5I, I8I-I88.

45 USDA, U. S. Department of Agriculture, Agricultural Research Service. Oxygen Radical Absorbance Capacity (ORAC) of Selected Foods, Release 2, http://oracdatabase.com (accessed January 20 I7).

46 M. H. Carlsen, B. L. Halvorsen, K. Holte, S. K. Bohn, S. Dragland, L. Sampson, C. Willey, H. Senoo, Y. Umezono, C. Sanada, I. Barikmo, N. Berhe, W. C. Willett, K. M. Phillips, D. R. Jacobs and R. Blomhoff, The total antioxidant content of more than 3100 foods, beverages, spices herbs and supplements used worldwide, Nutr. J., 2010, 9, 3-4l.

47 F. L. Chung, J. Schwartz, C. R. Herzog and Y. M. Yang, Tea and cancer prevention: studies in animals and humans, J. Nutr., 2003, 133, 3268-3274.

48 D. Erba, P. Riso, A. Bordoni, P. Foti, P. L. Biagi and G. Testolin, Effectiveness of moderate green tea consumption on antioxidative status and plasma lipid profile in humans, J. Nutr. Biochem., 2005, 16, 144-149.

49 X. Wang and E. K. Michaelis, Selective neuronal vulnerability to oxidative stress in the brain, Front Aging Neurosci., 2010, 2, 12.

50 K. Unno, A. Hara, A. Nakagawa, K. Iguchi, M. Ohshio, A. Morita and Y. Nakamura, Anti-stress effects of drinking green tea with lowered caffeine and enriched theanine, epigallocatechin and arginine on psychosocial stress induced adrenal hypertrophy in mice, Phytomedicine, 2016, 23, I365-I374.

5 I M. Vignes, T. Maurice, F. Lante, M. Nedjar, K. Thethi, J. Guiramand and M. Recasens, Anxiolytic properties of green tea poyphenol (-)-epigallocatechin gallate (EGCG), Brain Res., 2006, II I0, 102-II5. 
52 R. Shastry, S. D. Ullal, S. Karkala, S. Rai and A. Gadgade, Anxiolytic activity of aqueous extract of Camellia sinensis in rats, Indian J. Pharmacol., 2016, 48, 68I-686.

53 W. Dimpfel, A. Kler, E. Kriesl and R. Lehnfeld, Theogallin and L-theanine as active ingredients in decaffeinated green tea extract. I. Electrophysiological characterization in the rat hippocampus in vitro, J. Pharm. Pharmacol., 2007, 59, II3I-II36.

54 K. Kimura, M. Ozeki, L. R. Juneja and H. Ohira, L-theanine reduces psychological and physiological stress responses, Biol. Psychol., 2007, 74, 39-45.

55 D. A. Camfield, C. Stough, J. Farrimond and A. B. Scholey, Acute effects of tea constituents Ltheanine, caffeine, and epigallocatechin gallate on cognitive function and mood: a systematic review and meta-analysis, Nutr. Rev., 2014, 72, 507-522.

56 P. T. Quinlan, J. Lane, K. L. Moore, J. Aspen, J. A. Rycroft and D. C. O’Brien, The acute physiological and mood effects of tea and coffee: the role of caffeine level, Pharmacol., Biochem. Behav., 2000, 66, 1928.

57 M. Suganuma, A. Saha and H. Fujiki, New cancer treatment strategy using combination of green tea catechins and anticancer drugs, Cancer Sci., 201 I, 102, 317-323.

58 M. C. García-Rodríguez, R. E. Vilchez, T. Nicolás and M. A. Altamirano, El Green tea en la quimioprevención in vivo del daño genotóxico inducido por metales cancerígenos (cromo [VI]), Nutr. Hosp., 2012, 27, 1204-1212.

59 J. C. Hakim, Green tea consumption is associated with decreased DNA damage among GSTMI positive smokers regardless of their hOGGI genotype, J. Nutr., 2008, 138, I567-I57I.

60 C. S. Yang and H. Wang, Cancer preventive activities of tea catechins, Molecules, 2016, 2I, 1679.

$6 I$ M. Inoue, K. Tajima, M. Mizutani, H. Iwata, T. Iwase, S. Miura, K. Hirose, N. Hamajima and S. Tomonaga, Regular consumption of green tea and risk of breast cancer recurrence: follow-up study from the Hospital based Epidemiological Research Program at Aichi Cancer Center (HERPACC), Japan, Cancer Lett., 2001, 167, 175-182.

62 R. J. Rosengren, Catechins and the treatment of breast cancer: possible utility and mechanistic targets, Drugs, 2003, 6, 1073-1078.

63 S. A. Laurie, V. A. Miller, S. C. Grant and M. G. Kris, Phase I study of green tea extract in patients with advanced lung cancer, Cancer Chemother. Pharmacol., 2005, 155, 33-38.

64 I. A. Siddiqui, M. Asim, B. B. Hafeez, V. M. Adhami, R. S. Tarapore and H. Mukhtar, Green tea polyphenol EGCG blunts androgen receptor function in prostate cancer, FASEB J., 2010, 16, 57I-582.

65 M. Suganuma, A. Takahashi, T. Watanabe, K. lida, T. Matsuzaki, H. Y. Yoshikawa and H. Fujiki, Biophysical approach to mechanisms of cancer prevention and treatment with green tea catechins, Molecules, 2016, 21 , 1566.

66 G. Bianchi, J. Cerhan, A. Parker, S. Putnam, W. See, C. Lynchi and K. Cantor, Tea consumption and risk of bladder and kidney cancers in a population-based case control study, Am. J. Epidemiol., 2000, I5I, 377-383.

67 T. Yamamoto, S. Hsu, J. Lewis, J. Wataha, D. Dickinson, B. Singh, W. B. Bollag, P. Lockwood, E. Ueta, T. Osaki and G. Schuster, Green tea polyphenols causes differential oxidative environments in tumor versus normal epithelial cells, J. Pharmacol. Exp. Ther., 2003, 30I, 230-236.

68 M. J. Li, Y. C. Yin, J. Wang and Y. F. Jiang, Green tea compounds in breast cancer prevention and treatment, World J. Clin. Oncol., 2014, 5, 520-528.

69 B. N. Singh, S. Shankar and R. K. Srivastava, Green tea catechin, epigallocatechin-3-gallate (EGCG): mechanisms, perspectives and clinical applications, Biochem. Pharmacol., 201 I, 82, I807-I82I.

$70 \mathrm{~J}$. Yarmolinsky, G. Gon and P. Edwards, Effect of tea on blood pressure for secondary prevention of cardiovascular disease: a systematic review and meta-analysis of randomized controlled trials, Nutr. Rev., 20I5, 73, 236-246.

7I C. Tian, Q. Huang, L. Yang, S. Légaré, F. Angileri, H. Yang, X. Li, X. Min, C. Zhang, C. Xu, J. Yuan, X. Miao, M. A. He, T. Wu and X. Zhang, Green tea consumption is associated with reduced incident CHD and improved CHD-related biomarkers in the Dongfeng-Tongji cohort, Sci. Rep., 2016, 6, 24353. 
72 A. Kim, A. Chiu, M. K. Barone, D. Avino, F. Wang and C. I. Coleman, Green tea catechins decrease total and low density lipoprotein cholesterol: a systematic review and meta-analysis, J. Am. Diet. Assoc., 2011, III, I720-1729.

73 H. Samavat, A. R. Newman, R. Wang, J. M. Yuan, A. H. Wu and M. S. Kurzer, Effects of green tea catechin extract on serum lipids in postmenopausal women: a randomized, placebo-controlled clinical trial, Am. J. Clin. Nutr., 2016, 104, I67I-1682.

74 M. P. Almajano, R. Carbó, J. A. López Jiménez and M. H. Gordon, Antioxidant and antimicrobial activities of tea infusions, Food Chem., 2008, 108, 55-63.

75 W. Swen, Effects of green tea and EGCG on cardiovascular and metabolic health, J. Am. Coll. Nutr., 2007, 26, 373-388.

76 A. E. Koutelidakis, K. Argiri, M. Serafini, C. Proestos, M. Komaitis, M. Percorari and M. Kapsokefalou, Green tea, white tea, and Pelargonium purpureum increase the antioxidant capacity of plasma and some organs in mice, Nutrition, 2009, 25, 453-458.

77 P. Ruggiero, G. Rossi, F. Tombola, L. Pancotto, L. Lauretti, G. D. Giudice and M. Zoratti, Red wine and green tea reduce $\mathrm{H}$ pylori - or VacA-induced gastritis in mouse model, Word J. Gastroenterol., 2007, 13, 349-354.

78 P. W. West, T. C. Mathew, N. J. Miller and Q. Electricwala, The effect of green tea on the growth and morphology of methicillin-resistan and methicillin-susceptible Staphylococcus aureus, J. Nutr. Environ. Med., 200I, II, 263-269.

79 V. K. Juneja, M. L. Bari, Y. Inatsu, S. Kawamoto and M. Friedman, Control of Clostridium perfringens, spores by green tea leaf extracts during cooling and cooked ground beef, chicken, and pork, J. Food Prot., 2007, 70, 1429-1433.

80 M. Hirasawa and K. Takada, Multiple effects of green tea catechin on the antifungal activity of antimycotics against Candida albicans, J. Antimicrob. Chemother., 2004, 53, 225-229.

8 I S. M. Yi, J. L. Zhu, L. L. Fu and J. R. Li, Tea polyphenols inhibit Pseudomonas aeruginosa, through damage to the cell membrane, Int. J. Food Microbiol., 2010, I44, III-II7.

82 J. S. Jin, M. Touyama, T. Hisada and Y. Benno, Effects of green tea consumption on human fecal microbiota with special reference to Bifidobacterium, species, Microbiol. Immunol., 2012, 56, 729-739.

83 M. W. Siddiqui, S. J. P. Singh, P. K. Thakur, J. F. Ayala-Zavala, A. Singh and R. S. Dhua, Antimicrobial properties of teas and their extracts in vitro, Crit. Rev. Food Sci. Nutr., 2015, 56, I428-I439.

84 H. J. Lee, Y. N. Lee, H. N. Youn, D. H. Lee, J. H. Kwak, B. L. Seong, J. B. Lee, S. Park, I. S. Choi and C. S. Song, Anti-influenza virus activity of green tea by-products in vitro and efficacy against influenza virus infection in chickens, Poult. Sci., 2012, 91, 66-73.

85 C. Cabrera, R. Artacho and R. Giménez, Beneficial effects of green tea - a review, J. Am. Coll. Nutr., 2006, 25, 79-99.

86 B. M. Carneiro, M. N. Batista, N. C. S. Braga, M. L. Nogueira and P. Raha, The green tea molecule EGCG inhibits Zika virus entry, Virology, 2016, 496, 2I5-218.

87 M. S. Mahmood, J. L. Mártinez, A. Aslam, A. Rafique, R. Vinet, C. Laurido, I. Hussain, R. Z. Abbas, A. Khan and S. Al, Antiviral effects of green tea (camellia sinensis) against pathogenic viruses in human and animals (a mini-review), Afr. J. Tradit., Complementary Altern. Med., 2016, 13, 176-184.

88 A. Simpson, L. Shaw and A. J. Smith, The bioavailability of fluoride from black tea, J. Dent., 200I, 29, |5-2|.

89 B. Narotzki, A. Z. Reznick, D. Aizenbud and Y. Levy, Green tea: a promising natural product in oral health, Arch. Oral Biol., 2012, 57, 429-435.

90 H. A. Linke and R. Z. LeGeros, Black tea extract and dental caries formation in hamsters, Int. J. Food Sci. Nutr., 2003, 54, 89-95.

9I M. Okamoto, A. Sugimoto, K. P. Legun, K. Nakayama, A. Kamaguchi and N. Maeda, Inhibitory effect of green tea catechins on cysteine proteinases in Porphyromonas gingivalis, Oral Microbiol. Immunol., 2004, 19, 118-120. 
92 M. J. Lee, J. D. Lambert, S. Prabhu, X. F. Meng, H. Lu, P. Maliakal, C. T. Ho and C. S. Yang, Delivery of tea polyphenols to the oral cavity by green tea leaves and black tea extract, Cancer Epidemiol. Biomarkers Prev., 2004, 13, 132-137.

93 R. K. Harwnash, P. K. Mukherjee, A. Kar, S. Bahadur, N. A. Al-Dhabi and V. Duraipandiyan, Enhancement of photoprotection potential of catechin loaded nanoemulsion gel against UVA induced oxidative stress, J. Photochem. Photobiol., 2016, 160, 318-329.

94 S. Saric and R. K. Sivamani, Polyphenols and sunburn, Int. J. Mol. Sci., 2016, 17, I52I.

95 A. Gondoin, D. Grussu, D. Steward and G. J. McDougall, White and green tea polyphenols inhibit pancreatic lipase in vitro, Food Res. Int., 2010, 43, 1537-1544.

96 T. Murase, K. Misawa, S. Haramizu and T. Hase, Catechin induced activation of the LKBI/AMPactivated protein kinase pathway, Biochem. Pharmacol., 2009, 78, 78-84.

97 D. Türközü and N. A. Tek, A mini review of effects of green tea on energy expenditure, Crit. Rev. Food Sci. Nutr., 2017, 57, 254-258.

98 T. Suzuki, M. Pervin, S. Goto, M. Isemura and Y. Nakamura, Beneficial effects of tea and the green tea catechin epigallocatechin-3-gallate on obesity, Molecules, 2016, 21, 1305.

99 A. Rocha, A. P. Bolin, C. A. L. Cardoso and R. Otton, Green tea extract activates AMPK and ameliorates white adipose tissue metabolic dysfunction induced by obesity, Eur. J. Nutr., 20I6, 55, 223 I2244.

100 J. Söhle, A. Knott, U. Holtzmann, R. Siegner, E. Grönniger, A. Schepky, S. Gallinat, H. Wenck, F. Stäb and $M$. Winnefeld, White tea extract induces lipolytic activity and inhibits adipogenesis in human subcutaneous (pre)-adipocytes, Nutr. Metab., 2009, 6, 20.

I0I G. Zheng, K. Sayama, T. Okubo, L. R. Juneja and I. Oguni, Anti-obesity effects of three major components of green tea, catechins, caffeine and theanine, in mice, In Vivo, 2004, 18, 55-62.

102 M. J. Amiot, C. Riva and A. Vinet, Effects of dietary polyphenols on metabolic syndrome features in humans: a systematic review, Obes. Rev., 2016, 17, 573-586.

103 M. C. Sabu, K. Smitha and K. Ramadasan, Anti-diabetic activity of green tea polyphenols and their role in reducing oxidative stress in experimental diabetes, J. Ethnopharmacol., 2002, 83, 109-116.

104 M. G. Alves, A. D. Martins, N. F. Teixeira, L. Rato, P. F. Oliveira and B. M. Silva, White tea consumption improves cardiac glycolytic and oxidative profile of prediabetic rats, J. Funct. Foods, 20I5, 14, 102-1 10.

105 M. Yilmazer-Musa, A. M. Griffith, A. J. Michels, E. Schneider and B. Frei, Grape seed and tea extracts and catechin 3 -gallates are potent inhibitors of $\alpha$-amylase and $\alpha$-glucosidase activity, J. Agric. Food Chem., 2012, 60, 8924-8929.

106 M. A. Ferreira, D. M. Silva, A. C. de Morais, J. F. Mota and P. B. Botelho, Therapeutic potential of green tea on risk factors for type 2 diabetes in obese adults - a review, Obes. Rev., 2016, 17, 13161328.

107 L. Dudaric, A. Fuzinac-Smojver, D. Muhvic and J. Giacometti, The role of polyphenols on bone metabolism in osteoporosis, Food Res. Int., 2015, 77, 290-298.

108 C. L. Shen, J. Han, S. Wang, E. Chung, M. C. Chyu and J. J. Cao, Green tea supplementation benefits body composition and improves bone properties in obese female rats fed with high-fat diet and caloric restricted diet, Nutr. Res., 2015, 35, 1095-II05.

109 K. Naghma and H. Mukhtar, Tea polyphenols for health promotion, Life Sci., 2007, 8I, 5I9-533.

I 10 Y. Clement, Can green tea do that? A literature review of the clinical evidence, Prev. Med., 2009, 49, 83-87.

I I I S. M. Nabavi, M. Daglia, A. H. Moghaddam, S. F. Nabavi and V. Curti, Tea consumption and risk of ischemic stroke: a brief review of the literature, Curr. Pharm. Biotechnol., 20I4, 15, 298-303.

II 2 J. Renaud, S. F. Nabavi, M. Daglia, S. M. Nabavi and M. G. Martinoli, Epigallocatechin-3-Gallate, a promising molecule for Parkinson's disease?, Rejuvenation Res., 2015, 18, 257-269. 
II 3 A. Di Lorenzo, S. F. Nabavi, A. Sureda, A. H. Moghaddam, S. Khanjani, P. Arcidiaco, S. M. Nabavi and M. Daglia, Antidepressive-like effects and antioxidant activity of green tea and GABA green tea in a mouse model of poststroke depression, Mol. Nutr. Food Res., 2016, 60, 566-579.

II4 J. C. Jurado-Coronel, M. Ávila-Rodríguez, V. Echeverria, O. A. Hidalgo, J. González, G. Aliev and G. Barreto, Implication of green tea as a possible therapeutic approach for parkinson disease, CNS Neurol. Disord.: Drug Targets, 2016, 15, 292-300.

I I 5 Y. Xu, Y. Zhang, Y. Quan, W. Wong, J. Guo, R. Zhang, Q. Yang, R. Dai, P. L. McGeer and H. Qing, Epigallocatechin Gallate (EGcG) inhibits alpha-synuclein aggregation: a potential agent for Parkinson's disease, Neurochem. Res., 2016, 4I, 2788-2796.

II6 C. Masterjohn and R. S. Bruno, Therapeutic potential of green tea in non alcoholic fatty liver disease, Nutr. Rev., 2012, 70, 4I-46.

II7 A. Jain, C. Manghani, S. Kohli, D. Nigam and V. Rani, Tea and human health: the dark shadows, Toxicol. Lett., 2013, 220, 82-87.

II 8 J. M. Wang, B. Xu, J. Y. Rao, H. B. Shen, H. C. Xue and Q. W. Jian, Diet habits, alcohol drinking, tobacco smoking, green tea drinking, and the risk of esophageal squamous cell carcinoma in the Chinese population, Eur. J. Gastroenterol. Hepatol., 2007, 19, I7I-I76.

II 9 J. Malik, J. Szakova, O. Drabek, J. Balik and L. Kokoska, Determination of certain micro and macroelements in plant stimulants and their infusions, Food Chem., 2008, III, 520-525.

120 J. S. McKenzie, J. M. Jurado and F. De Pablos, Characterisation of tea leaves according to their total mineral content by means of probabilistic neural networks, Food Chem., 2010, 123, 859-864.

I2I K. F. Fung, Z. Q. Zhang, J. W. Wong and M. H. Wong, Fluoride contents in tea and soil from tea plantations and the release of fluoride into tea liquor during infusion, Environ. Pollut., 1999, 104, 197205.

I22 W. S. Shu, Z. Zhang, C. Lan and M. H. Wong, Fluoride and aluminium concentrations of tea plants and tea products from Sichuan Province, China, Chemosphere, 2003, 52, 1475-I 482.

123 Z. Xie, Z. Chen, W. Sun, X. Guo, B. Yin and J. Wang, Distribution of aluminum and fluoride in tea plant and soil of tea garden in Central and Southwest China, Chin. Geogr. Sci., 2007, 17, 376-382.

I 24 M. H. Wong, Z. Q. Zhang, J. W. Wong and C. Y. Lan, Trace metal contents (Al, Cu and Zn) of tea: tea and soil from two tea plantations, and tea products from different provinces of China, Environ. Geochem. Health, 1998, 20, 87-94.

I25 R. N. Gallaher, K. Gallaher, A. J. Marshall and A. C. Marshall, Mineral analysis of the types of commercially available tea, J. Food Compos. Anal., 2006, 19, 53-57.

I 26 S. Nookabkew, N. Rangkadilok and J. Satyavivad, Determination of trace elements in herbal tea products and their infusions consumed in Thailand, J. Agric. Food Chem., 2006, 54, 6939-6944.

127 E. Malinowska, I. Inklelewicz, W. Czarnowski and P. Szefer, Assessment of fluoride concentration and daily intake by human from tea and herbal infusions, Food Chem. Toxicol., 2008, 46, 1055-106I.

$128 \mathrm{~J}$. Song, H. Xu, F. Liu and L. Feng, Tea and cognitive health in late life: current evidence and future directions, J. Nutr., Health Aging, 2012, 16, 31-34.

129 T. Jian, B. W. Glickman and J. G. de Boer, Protective effect of green tea against benzo- $\alpha$-pyreneinduced mutations in the liver of Big Blue transgenic mice, Mutat. Res., 200I, 480, I47-I5I.

$130 \mathrm{H}$. Fujiki and M. Sumanuma, Green tea: an effective synergist with anticancer drugs for tertiary cancer prevention, Cancer Lett., 2012, 324, I19-125.

I3I S. Wofram, Effects of green tea and EGCG on cardiovascular and metabolic health, J. Am. Coll. Nutr., 2007, 26, 373-388.

I32 M. Boschmann and F. Thielecke, The effects of epigallocatechin- 3-gallate on themogenesis and fat oxidation in obese men: a pilot study, J. Am. Coll. Nutr., 2007, 26, 389-395.

I33 D. Richard, K. Kefi, U. Barbe, A. Poli, P. Bausero and F. Visioli, Weight and plasma lipid control by decaffeinated green tea, Pharmacol. Res., 2009, 59, 35I-354.

I34 Y. Hara, Tea catechins and their applications as supplements and pharmaceutics, Pharmacol. Res., 20II, 64, 100-104. 
I35 R. Hursel, W. Viechtbauer and A. G. Dulloo, The effects of catechin rich teas and caffeine on energy expenditure and fat oxidation: a meta-analysis, Obes. Rev., 20II, I2, 573-658.

I36 X. Tzounis, J. Vulevic, G. G. Kuhnl, T. George, J. Leonczak, G. R. Gibson, C. Kwik-Uribe and J. P. Spencer, Flavanol monomer-induced changes to the human faecal microflora, Br. J. Nutr., 2008, 99, 782792.

I37 L. Feng, X. Gwee and E. H. Kua, Cognitive function and tea consumption in community dwelling older Chinese in Singapore, J. Nutr., Health Aging, 2010, 14, 433-448.

I38 M. Salahinejad and F. Aflaki, Toxic and Essential Mineral Elements Content of Black Tea Leaves and Their Tea Infusions Consumed in Iran, Biol. Trace Elem. Res., 2010, 134, 109-II7.

I 39 M. M. Özcan, A. Ünver, T. Uçar and D. Arslan, Mineral content of some herbs and herbal teas by infusion and decoction, Food Chem., 2008, 106, II20-1I27.

I40 J. S. McKenzie, J. M. Jurado and F. De Pablos, Characterisation of tea leaves according to their total mineral content by means of probabilistic neural networks, Food Chem., 2010, 123, 859-864.

I4I D. L. McKay and J. B. Blumberg, The role of tea in human health: an update, J. Am. Coll. Nutr., 2002, $21,1-13$. 
Table I. Mineral content in green and white tea leaves.

\begin{tabular}{lllll}
\hline Element & Tea & Country & $\begin{array}{l}\text { Concentration } \\
(\mathbf{m g} / \mathbf{K g})\end{array}$ & Reference \\
\hline \multirow{2}{*}{ Chromium } & Green tea & China, Japan & $0.45-0.49$ & 118 \\
& Green tea & China, Japan & $0.24-0.29$ & 85 \\
& Green tea & China, Japan & $31.5-32.3$ & 118 \\
& Green tea & India, Japan & $23.1-36.5$ & 119 \\
& White tea & India, China, Indonesia & $17.6-31.6$ & 119 \\
& Green tea & China, Japan & $11-26$ & 120 \\
& White tea & China, Japan & $10-26$ & 120 \\
& Green tea & China & $217-344$ & 121 \\
& Green tea & China & $49-104$ & 122 \\
& Green tea & China & $8-626$ & 123 \\
& White tea & & $3-228$ & 18 \\
& Green tea & China & $160-1500$ & 123 \\
& Green tea & Turkey & $535-2086$ & 15 \\
& White tea & & $903-1026$ & 15 \\
& Green tea & India, Japan & $211-1045$ & 119 \\
& White tea & India, China, Indonesia & $293-479$ & 119 \\
& White tea & China, Japan & $337-1463$ & 120 \\
& Green tea & China, Japan & $385-2081$ & 120 \\
& Green tea & China, India, Japan, Indonesia & $390-1260$ & 17 \\
\hline
\end{tabular}


Table 2. Mineral content in green and white tea infusions.

\begin{tabular}{|c|c|c|c|c|}
\hline Element & Tea & Country & Concentration $(\mu \mathrm{g} / \mathrm{L})$ & Reference \\
\hline Chromium & Green tea' & China, India, Indonesia, Japan & $n d^{2}-6.91$ & 124 \\
\hline \multirow[t]{8}{*}{ Copper } & Green tea ${ }^{3}$ & China & $29-61$ & 124 \\
\hline & Green tea ${ }^{4}$ & China & $40-70$ & 125 \\
\hline & Green tea' & China, Sri Lanka, India, Indonesia, Japan, Tailandia & $40-240$ & 126 \\
\hline & & Turkey & & \\
\hline & & & & 15 \\
\hline & Green tea ${ }^{5}$ & & $3-285$ & \\
\hline & White tea ${ }^{5}$ & & $119-290$ & \\
\hline & Green tea ${ }^{6}$ & China, Sri Lanka, India, Kenya, Turkey & $33-191$ & 15 \\
\hline \multirow[t]{3}{*}{ Fluorine } & Green tea ${ }^{7}$ & China & $1650-1830$ & 121 \\
\hline & Green tea ${ }^{3}$ & China, Japan, Java, Sri Lanka, Vietnam & $590-2520$ & 127 \\
\hline & Green tea ${ }^{6}$ & India, Japan & $205-1009$ & 119 \\
\hline \multirow[t]{2}{*}{ Manganese } & Green tea ${ }^{5}$ & Turkey & $780-3890$ & 15 \\
\hline & White tea ${ }^{5}$ & & $227-499$ & 15 \\
\hline
\end{tabular}

\footnotetext{
' $2 \mathrm{~g}$ of tea / $50 \mathrm{~mL}$ of boiling double-distilled water. Infusion time: 15 minutes.

2 nd: not detectable.

${ }^{3} 2 \mathrm{~g}$ of tea / $200 \mathrm{~mL}$ of boiling distilled water. Infusion time: 5 minutes.

${ }^{4} 2.5 \mathrm{~g}$ of tea / $236 \mathrm{~mL}$ of boiling water. Infusion time: 3-6 minutes.

${ }^{5} \mathrm{I} \mathrm{g}$ of tea / $50 \mathrm{~mL}$ of boiling distilled water. Infusion time: 5 minutes.

${ }^{6} \mathrm{I} \mathrm{g}$ of tea / $50 \mathrm{~mL}$ of boiling distilled water. Infusion time: 5 minutes.

${ }^{7} 3 \mathrm{~g}$ of tea / $150 \mathrm{~mL}$ of boiling deionized distilled water. Infusion time: 4 minutes.
} 
Table 3. Main effect of EGCG and the other catechins presents in green tea $y$ white tea described in the most recent literature.

\begin{tabular}{|c|c|}
\hline Effect & Reference \\
\hline Antioxidant activity & 75 \\
\hline Potent antioxidant & 69 \\
\hline High anti-free radical activity & 128 \\
\hline Prevention of oxidative damage in healthy cells & 104 \\
\hline Protection of neurons against oxidative damage & 3 \\
\hline \multicolumn{2}{|l|}{ Reduction of toxicity generated by $\mathrm{H}_{2} \mathrm{O}_{2}$} \\
\hline \multicolumn{2}{|l|}{ Activation of Nrf2 factor } \\
\hline \multicolumn{2}{|l|}{ Metal chelating activity } \\
\hline Antiangiogenic activity & 69 \\
\hline Chemopreventive and anticancer effects & 129 \\
\hline Inhibition of cell proliferation (damaged cells) & 110 \\
\hline Promotion of healthy cell growth & 69 \\
\hline Induction of cell apoptosis & 19 \\
\hline Suppression of oncogenic transcription factors & 65 \\
\hline Inhibitory effects at metastatic level & 130 \\
\hline \multicolumn{2}{|l|}{ Inhibition of TNF $\alpha$ expression } \\
\hline Induction and inhibition of enzymes & 39 \\
\hline Inhibition of the activity of the chromosomal enzyme telomerase & 69 \\
\hline Inhibition of some protein kinases & 65 \\
\hline Induction/inhibition of enzymes involved in & 60 \\
\hline \multicolumn{2}{|l|}{ drugs metabolism } \\
\hline \multicolumn{2}{|l|}{ Inhibition of DNA methylation } \\
\hline \multicolumn{2}{|l|}{ Effect on RNA expression } \\
\hline Anti-inflammatory activity & 19,69 \\
\hline Detoxifying effect & 12,39 \\
\hline Activity related to lipemia & $|3|$ \\
\hline Reduction of intestinal absorption of lipids & 19 \\
\hline Promotion of fecal cholesterol excretion & 72 \\
\hline Inhibition of hepatic enzymes involved in & 73 \\
\hline \multicolumn{2}{|l|}{ cholesterol synthesis } \\
\hline Effects against obesity and metabolic syndrome & 132 \\
\hline \multicolumn{2}{|l|}{ Decrease of proliferation and differentiation of } \\
\hline adipocytes & 133 \\
\hline Promotion of lipogenesis & 19 \\
\hline Loss of weight & 134 \\
\hline Promotion of leptin release & 102 \\
\hline Increment of $\beta$-oxidation and thermogenesis & $97,98,109$ \\
\hline \multicolumn{2}{|l|}{ Antidiabetic activity } \\
\hline Improvement of insulin response & 8 \\
\hline Activation of the insulin signaling pathway & 81 \\
\hline Antimicrobial activity & $83,104,106,135$ \\
\hline Antiviral activity & $84,86,87$ \\
\hline Anti-osteoporosis activity & 107 \\
\hline Anti-allergenic activity & 10,39 \\
\hline Antiestrogenic activity & 10,110 \\
\hline Photoprotective activity & 93,94 \\
\hline Anticariogenic activity & 89 \\
\hline Prebiotic effect against Bifidobacterium & $82,136,137$ \\
\hline Neuroprotective effect & $55,12,115,128$ \\
\hline Anxiolytic effect & 50,115 \\
\hline
\end{tabular}


Table 4. Total antioxidant capacity of green tea compared to other foods (USDA, 20I0).45

\begin{tabular}{ll}
\hline Fresh product & $\begin{array}{l}\text { ORAC } \\
\mu \mathrm{mol} \mathrm{TE} / 100 \mathrm{~g}\end{array}$ \\
\hline Gren tea (infusion) ${ }^{2}$ & 1253 \\
Apple (different varieties) & $2573-4275$ \\
Apricot & 1115 \\
Red grape & 1746 \\
Kiwi & 862 \\
Raspberries & 5347 \\
Oranges (navels variety) & 1819 \\
Ananas & 385 \\
\hline
\end{tabular}

I TE: Trolox equivalent

${ }^{2}$ Infusion time: 3 minutes 